\title{
O DESIGN EMOCIONAL ASSOCIADO À APLICAÇÃO DE TEXTURAS BIOMIMÉTICAS EM SUPERFÍCIES MATERIAIS
}

\author{
Tatielle Haussen Reis \\ UFRGS \\ tatimsv@hotmail.com \\ Annelise Kopp Alves \\ UFRGS \\ annelise.alves@ufrgs.br
}

Resumo: O presente trabalho objetiva estudar uma aplicação biomimética, sustentada por estudos acerca dos passeriformes da espécie Sicalis flaveola (canário-da-terra), associada ao design de produtos conferindo a estes características intangíveis. $\mathrm{O}$ estudo dos elementos associados a biomimética se mostra relevante para o desenvolvimento de projetos que visem suprir as necessidades e exigências do mercado de consumo, considerando a associação com aspectos intangíveis, os quais interferem no significado simbólico do produto agregando valor emocional. No trabalho, busca-se o desenvolvimento de texturas baseadas na morfologia das penas do Sicalis flaveola para a aplicação em superfícies materiais, com base em análises macroscópicas e microscópicas de tais penas. Para isso, depois de definidas e aplicadas as texturas em chapas de diferentes materiais, estas foram disponibilizadas a um público específico para verificar a interação entre usuário e objeto proposto a partir da realização das técnicas de análises sensoriais e entrevistas. Durante a execução do trabalho foram utilizadas, ainda, diferentes técnicas metodológicas, tais como, revisão literária, estudo de campo e experimentação do produto. Por meio das pesquisas e estudos realizados, por fim, buscou-se compreender a interação do usuário com as texturas propostas para possível aplicação em projetos de produtos, verificando as percepções sensoriais associadas às mesmas que agregam valor aos produtos e interferem na decisão de compra.

Palavras-chave: Design emocional; Biomimética; Sicalis flaveola; Texturas; Análise Sensorial.

Abstract: This work aims to study a biomimetic application, supported by studies about the passerines Sicalis flaveola, associated with product design and intangible characteristics. The study of elements associated with biomimetic is important to development of projects that aim to meet the 
needs and demands of the consumer market, considering the association with intangibles aspects, which interfere in the symbolic means of products adding emotional value. In this specific work, textures were developed based on the morphology of the feathers of Sicalis flaveola applied to different materials surfaces, according with macroscopic and microscopic analysis that seek to highlight the main features of structural, functional and aesthetic of the feathers in study. For this, after defined and applied textures in samples of different materials, these were made available to consumers to verify the interaction between user and proposed object from the realization of sensory analysis techniques and interviews. During the execution of work were used also other different methodological techniques, research and analysis related to the object of study, such as literary review, field study and experimentation of product. Therefore, by means of these research and studies, the work sought to understand the user's interaction with the textures proposals for possible application in product design, verifying sensory perceptions associated with them that add value to products and influence the buying decision.

Palavras-chave: Emotional Design; Biomimetic; Sicalis flaveola; Textures; Sensory Analysis.

\section{INTRODUÇÃO}

Atualmente grande parte dos produtos tem sido desenvolvida e, em consequência, consumida como commodities. Os produtos comumente similares, cujas características estruturais e estéticas são parecidas, nesse contexto, competem por baixos custos e não possuem valor agregado. O consumidor, dessa forma, compra, usa e descarta o produto, aderindo a um ciclo vicioso que desconsidera a sua relação afetiva e vida útil. (NORMAN, 2004; BONSIEPE, 2011).

Durante o processo e concepção de um projeto, o designer é responsável por introduzir características significativas aos objetos, que interfiram nas suas condições de consumo e de uso. Assim, "o designer, como produtor das distinções visuais e da semântica da cultura cotidiana, influi nas emoções, nos comportamentos e nas atitudes do usuário" (BONSIEPE, 2011, p.116).

$\mathrm{Na}$ sociedade atual, o consumo parte principalmente das exigências pessoais do usuário, que envolvem tanto o racional, quanto o emocional, sendo, ao mesmo tempo, estimulado pela sua condição sócio-histórica, vinculada à cultura, faixa etária, instituições formadoras e classe social. Segundo LeDoux (2001), o ser humano toma a maioria de suas decisões seguido pelo lado emocional, sendo tão importante quanto à razão para a construção de uma vida saudável.

Nesse contexto, a aplicação de características percebíveis emocionalmente, de caráter não estrutural/físico (características intangíveis), é bastante importante para que os produtos passem a ter um valor agregado e possam se destacar dos demais. Essa tática viabiliza a interação satisfatória que permite a experiência de uso e relação afetiva do usuário com o produto, podendo evitar, simultaneamente, seu descarte precoce.

O design emocional pode ser concebido a partir da união adequada de critérios estéticos, simbólicos, funcionais e materiais, capazes de serem percebidos 
sensivelmente pelo usuário, seguindo os estágios de reconhecimento do produto, experimentação e, posterior, identificação, derivada da possível relação emocional proporcionada por este (NORMAN, 2004). O estímulo dos sentidos - visão, tato, olfato, paladar e audição - por meio dos quais se mantem contato direto com o mundo se torna essencial para a criação de projetos com características intangíveis agregadas.

Devido ao crescimento do setor industrial associado, principalmente, ao desenvolvimento de novos produtos, a seleção de materiais específicos e adequados à aplicação, conforme suas condições de uso é outro critério importante para a concepção coerente do produto. Os materiais provocam diferentes reações perceptíveis devido a sua composição estrutural que os caracterizam não apenas pela forma visual, mas também pela evocação de outros sentidos, principalmente o tátil. Através dessas percepções capazes de provocar, cada material define sua personalidade, que o identifica sensivelmente diante do público, causando consequentes assimilações de experiências. Dessa forma, os produtos necessitam cada vez mais da aplicação de materiais com diferentes texturas sensíveis ao toque, que sejam capazes de interferir na sensibilidade do usuário, como também, de caracterizálos (ASHBY; JOHNSON, 2011).

Para desenvolver e confeccionar projetos caracteristicamente emocionais e que considere a adequação de materiais podem ser utilizados diferentes recursos, como a análise e projeção de sistemas naturais, compreendidos pela biomimética, ciência que estuda os modelos da natureza, imitando-os ou inspirando-se neles para apresentar soluções eficazes as exigências humanas, ela propõe que além de extrair elementos da natureza pode-se também aprender com os princípios e sistemas dispostos pela mesma. Os sistemas naturais possuem estruturas e interfaces naturalmente constituídas, que facilitam o reconhecimento do usuário, tanto devido a suas definições estéticas beneficiadas pela proporção áurea, quanto pela concepção estrutural satisfatória e sustentável (BAXTER, 2000; BENYUS, 2007).

Os pássaros são exemplos de elementos naturais, que podem ser estudados para aplicação em conceitos ou projetos de demanda a partir de suas características morfológicas e de sobrevivência. Esses animais, pertencentes à classe dos passeriformes, possuem atributos instigantes, como a plumagem, constituída das penas, e o canto, na maioria, belo e atrativo. A maneira como vivem, sua reprodução, habitat e demais dependências de sua existência, também são aspectos relevantes de sua caracterização. Todos estes requisitos podem ser associados à produção de objetos de consumo, com o intuito de inferir, características perceptivas e intangíveis, capazes de cooperar com a satisfação do usuário (SANTOS, 1979; SICK, 1997).

O canário-da-terra (Sicalis flaveola) é uma das espécies de passeriformes conhecidas usualmente por seus atributos estéticos e pela beleza de seu canto. Sendo um pássaro considerado nativo do Brasil, o estudo de suas particularidades mostra-se bastante relevante para o âmbito da pesquisa. O Sicalis flaveola possui um porte pequeno, coloração amarelada nos machos e, pardacenta nas fêmeas. Ainda, seu canto é estimado como um dos mais belos e sua denominação - canário-da-terra - é relativa ao seu gosto por se sujar com a terra molhada (SICK, 1997).

Existe um campo amplo e diversificado para estudos nesta área que se provam importantes para o desenvolvimento de projetos com aspectos sensíveis ou emocionais atrelados, capazes de cooperar com a satisfação do usuário. Conforme visto, há uma necessidade árdua da associação de projetos de produtos e conceitos 
com características persuasivas e de identificação com o usuário, e a busca dessa solução em elementos predispostos pela natureza é promissora, devido à conexão prévia do usuário com os mesmos.

Sob estas condições, o objetivo geral do trabalho é, a partir da aplicação biomimética sustentada por estudos acerca da plumagem dos passeriformes da espécie Sicalis flaveola (canário-da-terra), associada ao design de produtos, conferir características intangíveis, capazes de atrair sensivelmente o público, aos objetos de consumo, especialmente relacionadas à aplicação de texturas em suas superfícies materiais, e verificar a interação entre usuário e o projeto biomimético desenvolvido.

Para a realização destes estudos foram definidas algumas restrições de conteúdo para pesquisa. Nesse caso, considerando as atribuições da plumagem dos pássaros, o trabalho foi direcionado ao estudo da morfologia das principais penas do Sicalis flaveola: penugem (peito), rêmige (asa) e retriz (rabo) (Figura 1).
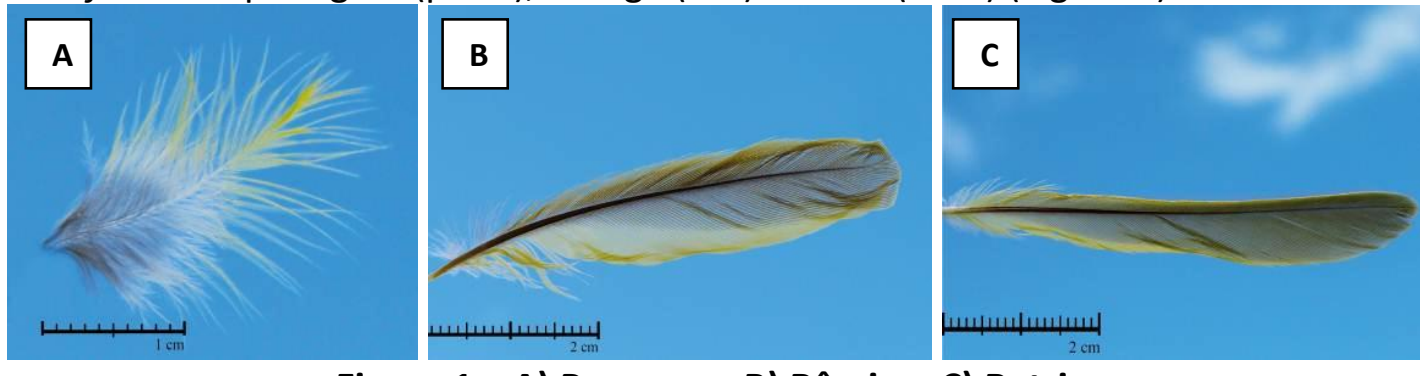

Figura 1 - A) Penugem; B) Rêmige; C) Retriz.

Fonte: Elaborado pelo autor, com base na pesquisa realizada.

De acordo com os objetivos do trabalho, foi utilizada como principal metodologia a pesquisa aplicada (LAKATOS; MARCONI, 2008), sustentada pela pesquisa exploratória (GIL, 2002), a qual envolve a pesquisa bibliográfica (GIL, 2002), e pela pesquisa descritiva (LAKATOS; MARCONI, 2008), que inclui o estudo de campo (GIL, 2002), as entrevistas (GASKELL, 2007) e as técnicas da metodologia para experimentação de produtos de Dischinger (2009) - análises experimentais e sensoriais.

As texturas foram desenvolvidas com base nos estudos de cada uma das penas, sendo aplicadas em chapas poliméricas, cerâmicas e metálicas. A aplicação dessas texturas às superfícies é importante para entender a interação do usuário com o material a partir das distintas configurações que ele pode apresentar, sendo possível compreender o nível de percepção destes em relação ao que lhe é proposto e se essas condições interferem na atribuição de aspectos emocionais. Dessa forma, é possível estabelecer associações com produtos para a caracterização, ou seja, personalização dos mesmos no mercado, conferindo um valor significativo ao usuário.

\section{Materiais e métodos}

O trabalho foi desenvolvido com base na pesquisa aplicada, que viabiliza sugestões às soluções de problemas proeminentes na área de estudo (LAKATOS; MARCONI, 2008). Em sequência, seguiu estruturado por uma metodologia específica para a experimentação de produtos, que propõe o desenvolvimento e confecção de corpos de prova e, posterior, análise de interação do público com os mesmos.

A pesquisa realizada foi inicialmente de caráter exploratório (GIL, 2002), sendo utilizada para a contextualização do tema, justificativa da pesquisa e de seus objetivos, como também, na busca de técnicas e conhecimentos já explorados na área de estudo. Durante o desenvolvimento do trabalho também foi empregada a pesquisa descritiva 
(LAKATOS; MARCONI, 2008), a qual relaciona-se com o estudo de campo, (GIL, 2002), neste contexto, associado à observação dos passeriformes, considerando a exploração de sistemas naturais. Ainda, essa técnica pode ser notada na aplicação das análises experimentais, sensoriais e entrevistas qualitativas.

Em conjunto à observação foram coletadas amostras de penas da espécie estudada, sendo recolhidas ao menos uma de cada designação da plumagem. Com estas amostras foram feitas análises em escala macroscópica e microscópica, realizadas, respectivamente, a olho nu com base na manipulação manual das penas e em um Microscópio Eletrônico de Varredura (MEV).

Para a confecção e caracterização das amostras, as texturas foram definidas com base nas imagens obtidas por MEV, apresentando propriedades de acordo com a proporção áurea. As amostras foram definidas digitalmente conforme a constituição do retângulo áureo, a medida padrão instituída foi aproximadamente 4,7 x 7,6cm. Em seguida ao trabalho de desenvolvimento digital das amostras, as texturas foram aplicadas em chapas de três diferentes materiais (metal, cerâmica e polímero), visando o entendimento da distinção de percepção nas três grandes classes dos materiais.

As chapas poliméricas de PMMA (acrílico) foram confeccionadas com o uso do processo de corte e gravação a laser, sendo utilizada uma máquina de $60 \mathrm{~W}$ de potência com lente de $100 \mathrm{~mm}$. Os quatro modelos de peças definidas foram criados com os parâmetros correspondentes ao melhor resultado conforme o objetivo desejado, sendo utilizada uma potência máxima de $90 \%$ e uma velocidade de 50 $\mathrm{m} / \mathrm{min}$, para esta definição, foram feitos testes de aplicação de diferentes parâmetros.

Para a concepção das chapas cerâmicas foi utilizado o processo de decalque. Nesse caso, as matrizes confeccionadas com gesso foram feitas com moldes de PMMA gravados a laser, com tamanho $5 \%$ maior do que o desejado, considerando a retração durante a queima das peças finais. Quando prontas e totalmente secas, as matrizes foram prensadas no material cerâmico faiança branca, preparado de acordo com tamanho e espessura desejados, obtendo-se a amostra cerâmica com as características projetadas e esperadas. Por fim, as peças foram queimadas em um forno a uma temperatura de $900^{\circ} \mathrm{C}$ com um patamar de $150^{\circ} \mathrm{C} / \mathrm{h}$.

A confecção das amostras de metal foi feita por meio do processo de fundição. Por se tratar de peças planas, com formato de pequenas chapas, porém com certa complexidade superficial apresentada pelas texturas, o processo de fundição empregado durante o trabalho foi similar ao de fundição em molde de areia. Nesse caso, o molde utilizado foi desenvolvido com uma mistura de gesso, cimento e cal, conferindo à sua estrutura, respectivamente, boa precisão e acabamento, resistência e elasticidade. A mistura foi composta por $1 / 3$ de cada um dos materiais, sendo adicionada água à sua composição. Os modelos das peças confeccionados em acrílico pelo processo de gravação e corte a laser, foram disponibilizados em suportes, onde despejou-se a mistura, formando os moldes para posterior realização da fundição.

Os materiais utilizados na confecção, chumbo e estanho, foram aquecidos em um cadinho até alcançarem seu ponto de fusão. Ao mesmo tempo, para evitar o choque térmico e a formação de bolhas nas amostras, os moldes também foram submetidos ao aquecimento. Por fim, o material metálico derretido foi vertido nos moldes aquecidos com aplicação de um movimento de vibração constante, que evitava a formação de deformidades e porosidade nas peças. Após o resfriamento, algumas imperfeições das amostras foram lixadas, conferindo um melhor acabamento. 
Para finalizar, o presente trabalho teve como base, ao auxílio de análise de texturas, a metodologia proposta por Dischinger (2009) e as entrevistas (GASKELL, 2007), que orientam durante a avaliação de características do projeto. Como material de apoio à metodologia, foram utilizadas outras fontes bibliográficas que apontam o processo de análise sensorial e complementam o sentido do trabalho. A partir dessa aplicação, é possível compreender as relações existentes entre usuário e produto de acordo com a experiência proporcionada.

Com a realização da análise sensorial é possível averiguar características associadas aos produtos, como a sua posição em relação aos concorrentes, seu diferencial, possíveis falhas, sua aceitabilidade, os aspectos racionais e irracionais, dentre outras atribuições relativas à reação sensorial provocada durante o contato entre o usuário e o produto. Para isso, utilizou-se como base testes afetivos (testes de classificação afetiva e testes com escalas hedonísticas), os quais condizem com provas sensoriais utilizadas para a valorização de preferência ou aceitação do produto (IFT, 1981; NORONHA, 2003; ESTEVES, 2009). Para a compreensão inicial dos resultados, as análises sensoriais e entrevistas foram realizadas de forma preliminar, com um número pequeno de participantes, sendo viável posterior ampliação desses estudos.

A seleção dos avaliadores para os testes afetivos introdutórios foi direcionada a indivíduos de diversas cidades da região sul do Brasil, priorizando consumidores de diferentes faixas etárias, classes sociais e grupos de convívio, que não tinham prévio conhecimento acerca do trabalho realizado, evitando influência nos resultados, e que concordassem com as atividades de análises propostas. Ainda, durante a seleção dos avaliadores, foram relevados alguns critérios de interesse, como disponibilidade de tempo, saúde e limitação sensorial (DISCHINGER, 2009; ESTEVES, 2009).

As análises iniciais, realizadas pelo total de 19 avaliadores, foram aplicadas de maneira individual, variando de acordo com a disponibilidade de cada um. Durante o processo de análise, os avaliadores tiveram contato direto com todas as amostras desenvolvidas e analisaram separadamente de maneira ordenada suas texturas e materiais, definindo os resultados de preferências e aceitação em relação às mesmas.

Depois da análise sensorial foram preparadas as entrevistas qualitativas com roteiro semiestruturado para aplicação a um grupo de indivíduos selecionados conforme os critérios propostos. Essas entrevistas têm como objetivo intensificar a análise das principais reações de interação apresentadas pelos entrevistados em relação às texturas propostas, proporcionando a compreensão do nível de percepção dos mesmos conforme sua associação com aspectos intangíveis.

A escolha dos entrevistados foi feita a partir do processo de seleção da análise sensorial, sendo escolhido um número reduzido de indivíduos dentre os avaliadores participantes da etapa de análise antecedente, no total 14, que apresentaram variação de análises mais significativas. Neste caso, as amostras foram disponibilizadas da mesma maneira dos testes anteriores e as entrevistas foram realizadas no mesmo local, porém em momentos diferentes das análises sensoriais - após a verificação dos dados de maior coerência e do consentimento dos entrevistados.

\section{CONCLUSÃO}

\subsection{Análises Microscópicas}

A primeira análise microscópica realizada foi a da pena retriz (Figura 2). Durante sua visualização é possível perceber a organização rígida das barbas e 
barbicelas, que se repete conforme a ampliação microscópica, diferenciando-se somente nas extremidades da raque, parte em que os vexilos inferiores encontram-se estruturados de forma mais aleatória. Essa organização é apresentada no sentido diagonal em linhas paralelas, formando uma estrutura mecânica e visual relevante.
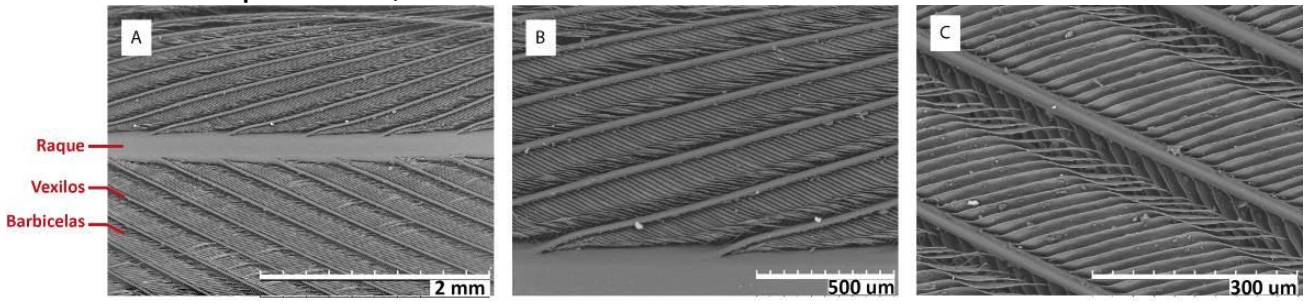

Figura 2 - MEV de pena retriz do Sicalis flaveola. A) Imagem central da estrutura da pena (50x); B) Detalhe da formação dos vexilos superiores a partir da haste (120x);

C) Detalhe dos vexilos superiores (300x).

Fonte: Elaborado pelo autor, com base na pesquisa realizada.

Em seguida, foi realizado o processo de análise microscópica da pena rêmige. Suas características microscópicas são bastante semelhantes as da pena retriz (Figura 3). Sua estrutura é perfeitamente organizada, sendo seus vexilos dispostos de forma diagonal em um crescimento contínuo, tal como acontece com suas barbas e barbicelas. O desdobramento dos vexilos da raque, organizado de maneira uniforme, também se destacam como critério importante à composição geral da pena.
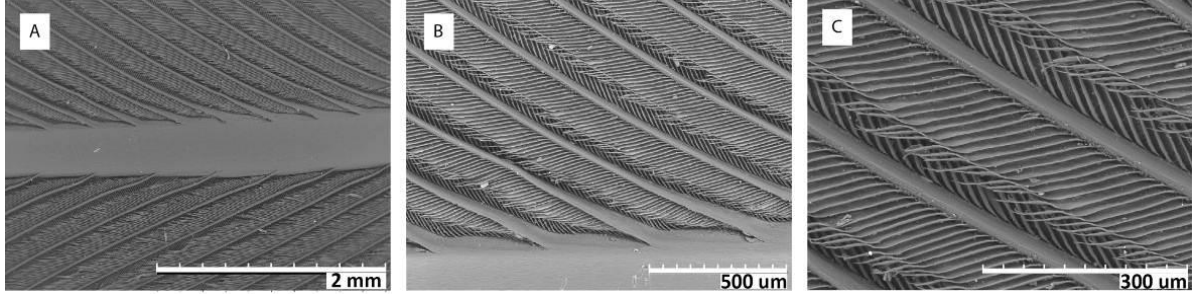

Figura 3 - MEV da rêmige do Sicalis flaveola. A) Imagem central da estrutura da pena

(50x); B) Detalhe da formação dos vexilos superiores a partir da haste (120x); C) Vexilos superiores (300x).

Fonte: Elaborado pelo autor, com base na pesquisa realizada.

A última análise de MEV (Figura 4) foi realizada com a penugem do Sicalis flaveola. Apesar do aparecimento de barbas e barbicelas irregulares, as quais não possuem uma organização fixa, os vexilos da pena analisada indicam uma ordem constituinte, formando uma favorável estruturação estética. Ao contrário das penas estudadas anteriormente, os vexilos e barbas padronizados possuem um espaçamento relevante entre eles, característica provocada devido à formação subsequente das barbicelas esvoaçantes e sutilmente desordenadas.
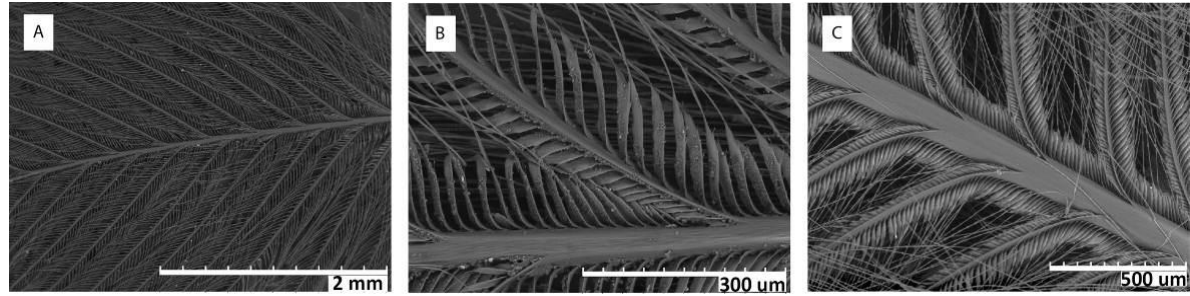

Figura 4 - MEV de penugem do Sicalis flaveola. A) Imagem central da estrutura da pena (50x); B) Detalhe da formação dos vexilos superiores a partir da haste (300x);

C) Detalhe dos vexilos superiores (120x).

Fonte: Elaborado pelo autor, com base na pesquisa realizada. 


\subsection{Caracterização e confecção dos corpos-de-prova}

A Figura 5 indica as amostras projetadas digitalmente para posterior aplicação. Estas foram desenvolvidas a partir da manipulação das imagens microscópicas que representam de forma coerente as propriedades estruturais associadas a cada uma das penas estudadas.
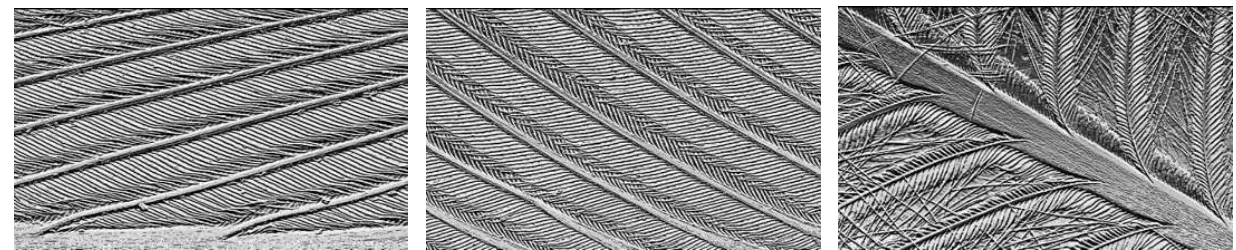

Figura 5 - A) Padrão de textura com base na pena retriz; B) Padrão de textura de acordo com a pena rêmige; C) Padrão de textura definido a partir da penugem.

Fonte: Elaborado pelo autor, com base na pesquisa realizada.

No geral, as amostras apresentaram características superficiais semelhantes em todos os materiais de aplicação, possuindo propriedades de acordo com as expectativas do trabalho, as quais absorveram o máximo de detalhes das texturas desenvolvidas digitalmente. Conforme observado nas figuras a seguir, as amostras poliméricas, cerâmicas e metálicas apresentaram uma vistosa projeção da textura visual, além disso, uma formação sutil das características de rugosidade da superfície.

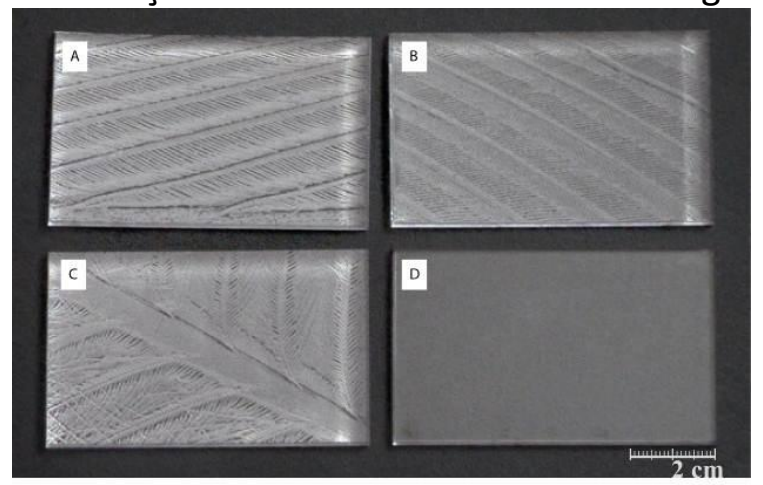

Figura 6 - Amostras poliméricas desenvolvidas com base na plumagem do Sicalis flaveola: A) Pena retriz; B) Pena regime; C) Penugem; D) Superfície lisa.

Fonte: Elaborado pelo autor, com base na pesquisa realizada.

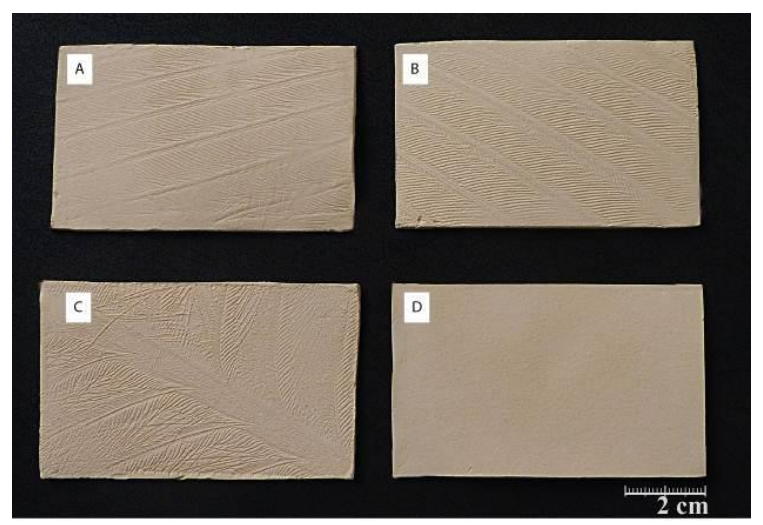

Figura 7 - Amostras cerâmicas desenvolvidas com base na plumagem do Sicalis flaveola: A) Pena retriz; B) Pena regime; C) Penugem; D) Superfície lisa. Fonte: Elaborado pelo autor, com base na pesquisa realizada. 


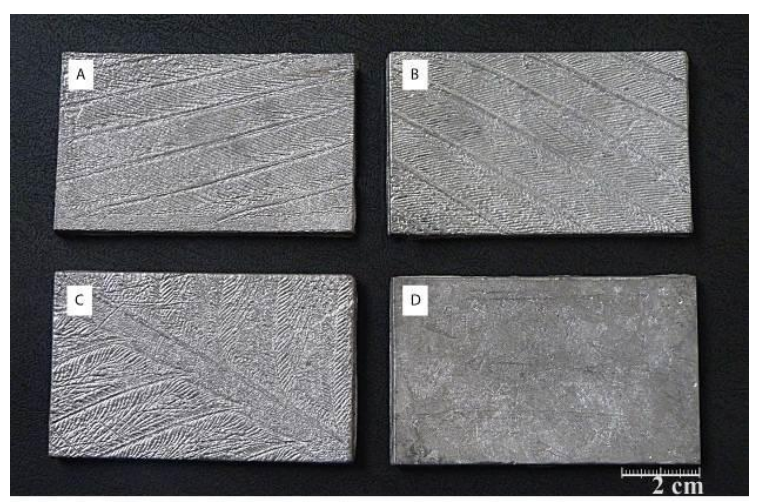

Figura 8 - Amostras cerâmicas desenvolvidas com base na plumagem do Sicalis flaveola: A) Pena retriz; B) Pena regime; C) Penugem; D) Superfície lisa.

Fonte: Elaborado pelo autor, com base na pesquisa realizada.

\subsection{Análises sensoriais e entrevistas}

A partir das análises sensoriais e entrevistas preliminares realizadas até 0 momento foi possível a obtenção de dados relevantes para a satisfação dos objetivos do trabalho, como a verificação do grau de preferência e aceitação das amostras desenvolvidas em diferentes situações e a compreensão das características tangíveis e intangíveis associadas às mesmas, considerando suas texturas e materiais.

\subsubsection{Disponibilização das amostras nas análises sensoriais e entrevistas}

Para a realização dos testes preliminares, em todas as categorias, as amostras foram disponibilizadas na mesma ordem para não ocorrer conflito de organização e computação dos resultados (Figura 9). Os códigos das amostras são compostos por uma letra e um algarismo: as letras indicam o tipo de material - A representando as amostras poliméricas, $B$ as amostras poliméricas e $C$ as amostras cerâmicas. Os números indicam: 1- pena retriz; 2- penugem; 3- pena rêmige e; 4- superfície lisa.

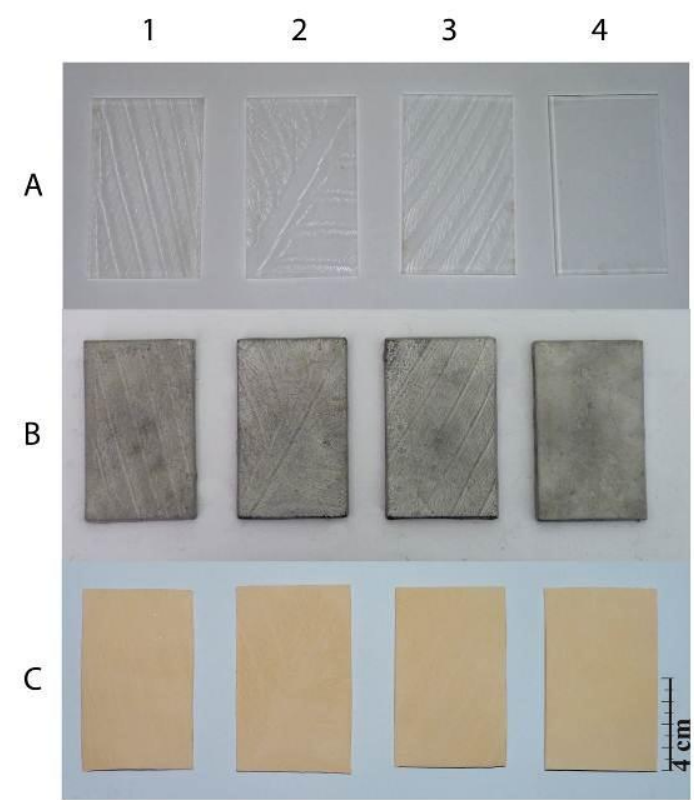

Figura 9 - Sequência de disposição das amostras.

Materias: (A) Polimero; (B) Metal; (C) Cerâmica.

Texturas: (1) Pena retriz; (2) Penugem; (3) Pena rêmige; (4) Superfície lisa.

Fonte: Elaborado pelo autor, com base na pesquisa realizada. 


\subsubsection{Testes de classificação afetiva}

A avaliação e preenchimento da ficha de avaliação afetiva foi realizada pelos avaliadores de forma que o nível de preferência deveria ser selecionado em uma escala de 4 a 1 , sendo 4 o grau mais atraente e 1 o menos atraente. A partir dessa conceituação, é possível identificar quais das amostras são de maior agrado para os avaliadores e se existe uma diferença acentuada dentre as suas análises. Com os resultados dos testes foi computada a média final de preferência de cada amostra, bem como, dos conjuntos das amostras conforme as classes de materiais (Figura 10).

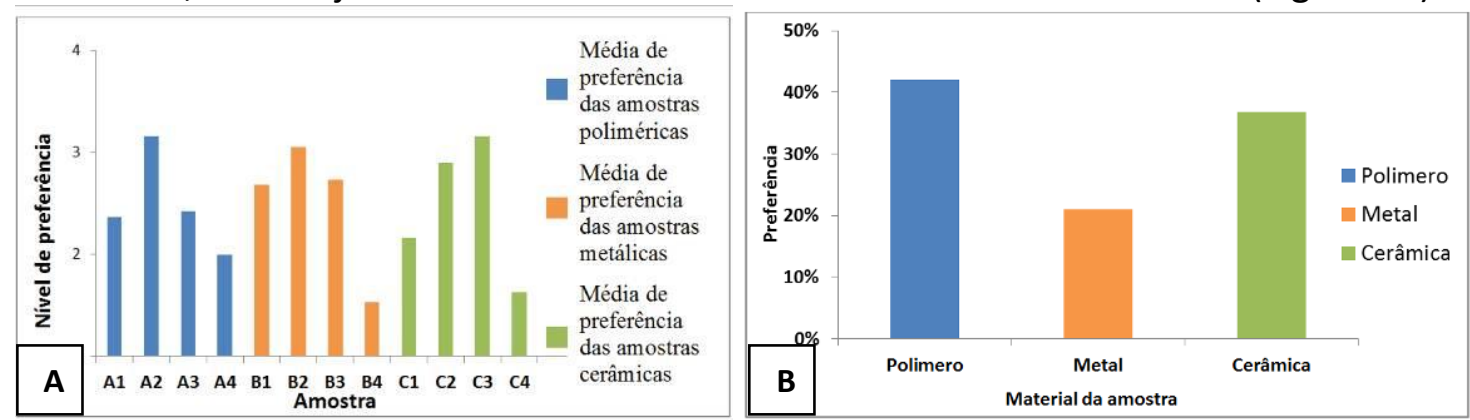

Figura 10 - A) Média de preferência classificativa das amostras na escala variável de 01 a 04; B) Preferência dos grupos das amostras conforme o material. Fonte: Elaborado pelo autor, com base na pesquisa realizada.

\subsubsection{Testes afetivos com escalas hedonísticas}

A avaliação e preenchimento da ficha de avaliação afetiva hedonística, foi realizada pelos avaliadores de forma que o nível de preferência deveria ser selecionado em uma escala de 9 a 1 , sendo 9 o grau mais alto - referente a opinião "gosto totalmente" - e 1 o grau mais baixo - referente a opinião "desgosto totalmente".

Os avaliadores demonstram opiniões diversas em relação à classificação de aceitação das amostras de acordo com as escalas disponibilizadas. Cada avaliador fez referência aos testes anteriores de classificação afetiva, seguindo uma padronização quanto à conceituação. De modo geral, o nível de avaliação das amostras foi positivo, em poucas situações os avaliadores indicaram um grau de aceitação baixo (inferior a 5), sendo a maioria bem conceituadas. Na Figura 11 é possível identificar a média de preferência das amostras analisadas, realçando o que representam aos entrevistados.

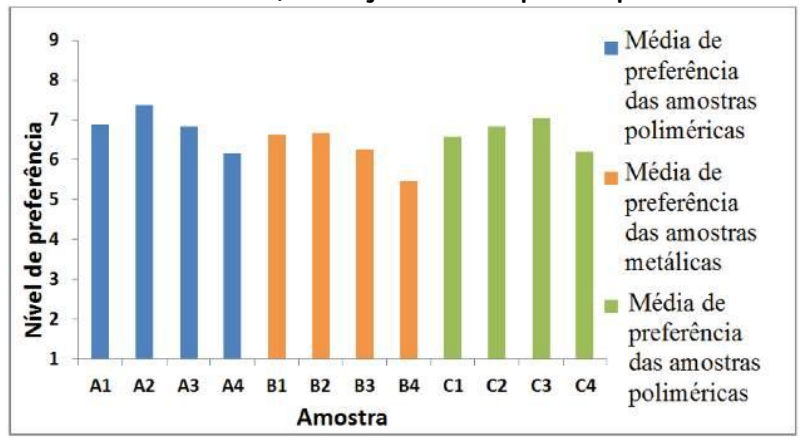

Figura 11 - Média de preferência das amostras na escala variável de 01 a 09.

Fonte: Elaborado pelo autor, com base na pesquisa realizada.

\subsubsection{Entrevistas qualitativas}

De forma geral, os entrevistados relataram que as amostras apresentadas possuem relação com lembranças e experiências anteriores. Somente 5,27\%, o que corresponde a um entrevistado, responderam que as amostras não representam associação com alguma coisa específica, porém consideram o conjunto apresentado de 
seu agrado. Por outro lado, o restante $(94,73 \%)$ indica diferentes correlações com as amostras, principalmente tratando-se de elementos da natureza.

Nas figuras a seguir é possível observar alguns resultados diagnosticados com base nas entrevistas. Dentre estes resultados destacam-se: a associação das amostras e texturas com experiências anteriores específicas, o nível de identificação dos entrevistados com as amostras, as diferenças de percepção tátil e visual de acordo com os diferentes materiais de aplicação das amostras e suas texturas, e a possibilidade de aplicação dessas texturas em projetos de produtos.
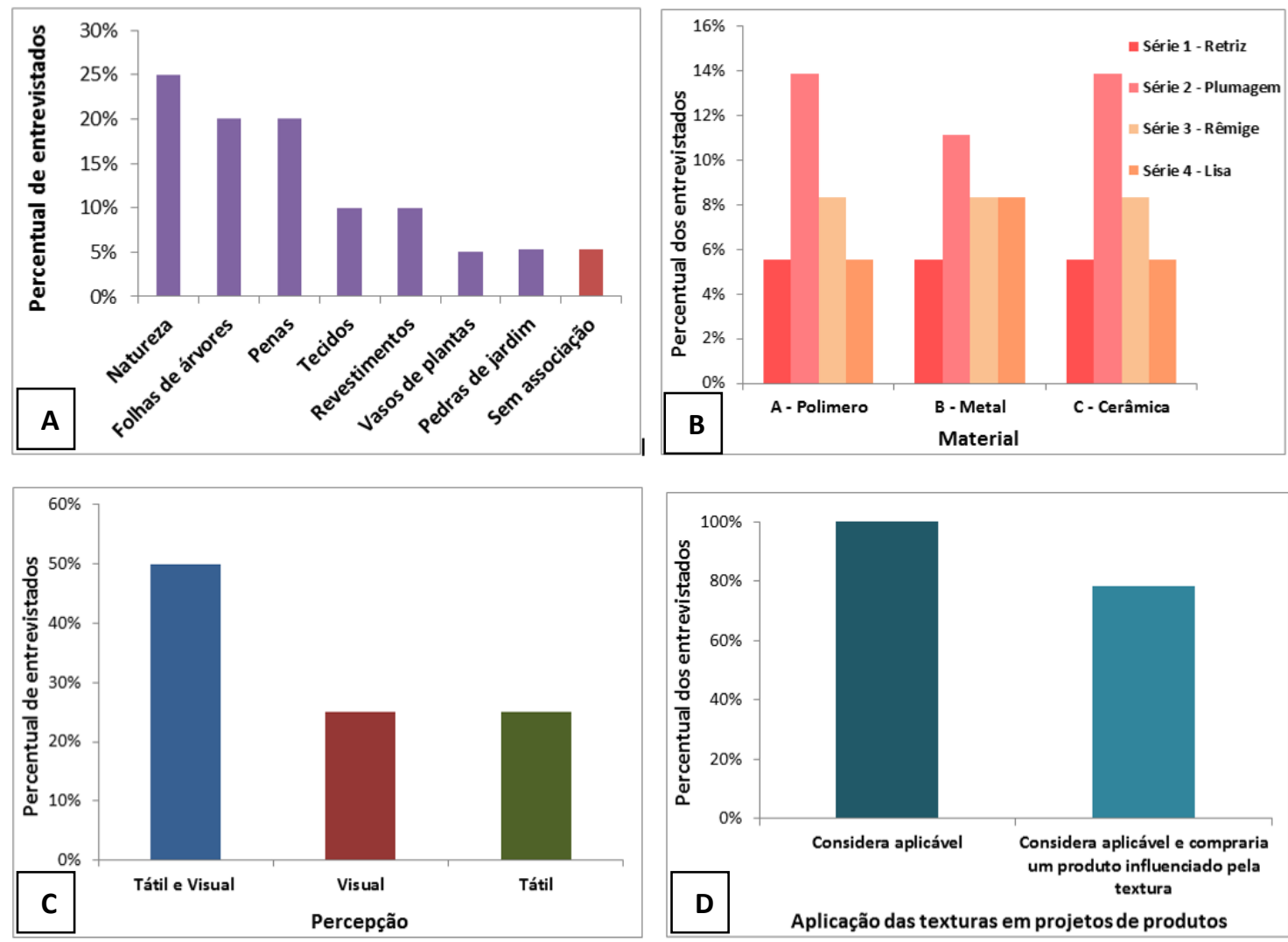

Figura 12 - Resultados das entrevistas. A) Relato de associação com experiências específicas; B) Identificação dos entrevistados com as amostra; C) Diferença de percepção visual e/ou tátil das amostras; D) Possibilidade de aplicação das texturas propostas em projetos de produtos.

Fonte: Elaborado pelo autor, com base na pesquisa realizada.

De acordo com os estudos foi possível perceber que não houve uma preferência unânime dos entrevistados em relação às amostras, cada um demonstrou diferentes gostos tanto direcionado às texturas, quanto aos materiais. As divergências ocorrem devido às influências, grupos de convívio e experiências que proporcionam diferentes concepções pré-estabelecidas, as quais interferem na decisão de escolha. Apesar de haver distinção na preferência das amostras, no geral, o grupo analisado apresentou uma boa avaliação das mesmas em todas as etapas de análise, mostrandose relevante a continuação dos estudos, bem como, das análises sensoriais e entrevistas na área.

Foi possível identificar também que existe uma afeição maior pelas superfícies texturizadas do que pelas superfícies lisas, sem nenhuma aplicação. No geral, conforme indicado nas entrevistas, texturas projetadas de forma coerente, que busquem uma boa concepção estética e sensível apresentam resultados satisfatórios 
quando empregados em produtos. Ainda, destaca-se que objetos com texturas agregadas são lembrados com facilidade devido à experiência de uso que provocam.

As superfícies texturizadas se provam importantes para a confecção de produtos com valores emocionais agregados. O consumidor não se desfaz daquilo que gosta, nesse sentido, tais características podem influenciar na decisão de escolha do produto, como também, nas condições de seu posterior descarte. Nesse caso, o consumo por objetos deixa de ser uma necessidade ou uma satisfação básica e instantânea e se torna um desejo, melhorando as condições do mercado de consumo.

\section{REFERÊNCIAS}

ASHBY, M. F.; JOHNSON, K. Materiais e Design: Arte e ciência da seleção de materiais no design de produto. Rio de Janeiro: Elsevier, 2011.

BAUER, M. W.; GASKELL, G. Pesquisa qualitativa com texto, imagem e som: um manual prático. Petropolis: Vozes, 2002.

BAXTER, M. Projeto de Produto: Guia prático para o desenvolvimento de novos produtos. São Paulo: Edgard Blucher, 2000.

BENYUS, J. M. Biomimética: Inovação Inspirada pela Natureza. São Paulo: Editora Cultrix, 2007.

BONSIEPE, G. Design, Cultura e Sociedade. São Paulo: EDGARD BLUCHER, 2011.

DISCHINGER, M. C. T. Metodologia de análise sensorial tátil em diferentes classes de materiais e texturas para aplicação no design de produtos. Dissertação de mestrado Universidade Federal do Rio Grande do Sul. Escola de Engenharia e Faculdade de Arquitetura. Programa de Pós-Graduação em Design, Porto Alegre, 2009.

ESTEVES, E. Análise Sensorial. Apontamentos para as aulas teóricas de Análise Sensorial do Curso de Engenharia Alimentar. Universidade do Algarve - Instituto Superior de Engenharia, 2009.

IFT (Institute of Food Science and Technology ). Sensory evaluation guide for testing food and beverage products. Sensory Evaluation Division, Institute of Food Technologists. Food Technology 35(11): 50-59, 1981.

GIL, A. C. Como elaborar projetos de pesquisa. São Paulo: Atlas, 2002.

LAKATOS, E. M.; MARCONI, M. DE A. Técnicas de Pesquisa. São Paulo: Atlas, 2008.

LEDOUX, J. Cérebro Emocional, O: Os misteriosos alicerces da vida emocional. Rio de Janeiro: Editora Objetiva, 2001.

NORMAN, D. A. Emotional Design: Why We Love (Or Hate) Everyday Things. New York: Basic Books, 2004.

NORONHA, J.F. Análise Sensorial - Metodologia. Apontamento de Análise Sensorial. Escola Superior Agrária de Coimbra, 2003.

SICK, H. Ornitologia Brasileira. 2o ed. Rio de Janeiro: Nova Fronteira, 1997.

SANTOS, E. Pássaros do Brasil. Belo Horizonte: Editora Itatiaia, 1979. 